\title{
¿Restringen los colegios de periodistas el derecho a la libertad de expresión?
}

\author{
Víctor J. Barrantes Calderón ${ }^{1}$
}

En este ensayo vamos a discutir si los colegios de periodistas en ciertos países de América Latina restringen el derecho del individuo a la libertad de expresión.

Para aproximarnos al tema la primera pregunta a la que debemos dar respuesta es ¿qué establecen las leyes en aquellos países donde existen los colegios de periodistas? Como regla general se puede decir que en cada caso estudiando (Chile, Colombia, Costa Rica, República Dominicana, Honduras, Nicaragua., Perú y Venezuela) la Constitución política de cada uno de esos países protege de manera clara el derecho el derecho del individuo de expresar sus pensamientos de forma oral o por escrito sin recibir ningún tipo de censura o restricción. Además., todas las legislaciones protegen el derecho de transmitir información a otros.

\footnotetext{
'Historiador y periodista. Ha laborado en diferentes medios de comunicación del país y desde 1994 lo hace para la Universidad Nacional.
} 
El artículo 29 de la Constitución Política de Costa Rica establece que 'Todos pueden comunicar sus pensamientos de palabra o por escrito, y publicarlos sin previa censura; pero serán responsables de los abusos que cometan en el ejercicio de este derecho, en los casos y del modo que la ley establezca" ${ }^{2}$. En el mismo sentido, el artículo 20 de la Constitución Política de Colombia garantiza a toda persona "la libertad de expresar y difundir su pensamiento y opiniones, la de informar y recibir información veraz e imparcial, y la de fundar medios masivos de comunicación...

En Chile, el artículo 19 de su Constitución le asegura a todas las personas, entre otras cosas, "La libertad de emitir opinión y la de informar, sin censura previa, en cualquier forma y por cualquier medio, sin perjuicio de responder de los delitos y abusos que se cometan en el ejercicio de estas libertades, en conformidad a la ley... ${ }^{4}$

El artículo 6 (Título II, Sección I) de la Constitución de República Dominicana establece: "Toda persona podrá, sin sujeción a censura previa, emitir libremente su pensamiento mediante palabras escritas o por cualquier otro medio de expresión, gráfico u oral..."

La Constitución de Honduras dicta "Es libre la emisión del pensamiento por cualquier medio de difusión, sin previa censura. Son responsables ante la ley los que abusen de este derecho y aquellos que por medios directos o indirectos restrinjan o impidan la comunicación y circulación de ideas y opiniones (Artículo 72): ${ }^{6}$

\footnotetext{
${ }^{2}$ Constitución Política de la República de Costa Rica de 1949 con sus reformas hasta 2003. Tomado de http://www.georgetowaedu/pdba/Constitutions/Costa/cosía2.htnil, 9 de mayo de 2005.

${ }^{3}$ Constitución de 1991 con reformas hasta 2005 de la República de Colombia. Tomado de: httpy/www.georgetovra.eda'pdba/Constitutions/Colonibia/col91.html, 9 de mayo de 2005

${ }^{4}$ Constitución Política de Chile- Tomado de http://www.cámara.cl/legis/const/c03.htm, 9 de mayo de 2005.

${ }^{5}$ Constitución de la República Dominicana. Tomado de http:/www.georgetown-edu/pdba/ Constitutions/DomRep/domrep94.html, 9 de mayo de 2005.

${ }^{6}$ Constitución de la República de Honduras de 1982, tomado de http://wwwhonduras.net/ honduras_constitutioahtml, 9 de mayo de 2005.
} 
Los artículos 30 y 66 de la Constitución también garantiza a los nicaragüenses el "derecho a expresar libremente su pensamiento en público o en privado, individual o colectivamente, en forma oral, escrita o por cualquier otro medio" y el derecho a la información veraz. "Este derecho comprende la libertad de buscar, recibir y difundir informaciones e ideas, ya sea de manera oral, por escrito, gráficamente o por cualquier otro procedimiento de su elección"7

El artículo 2 de la Constitución de Perú le otorga a toda persona el derecho "A las libertades de información, opinión, expresión y difusión del pensamiento mediante la palabra oral o escrita o la imagen, por cualquier medio de comunicación social, sin previa autorización ni censura ni impedimento algunos, bajo las responsabilidades de ley..."

Finalmente, en la República Bolivariana de Venezuela, el artículo 57 de su Constitución expresa que "Toda persona tiene derecho a expresar libremente sus pensamientos, sus ideas u opiniones de viva voz, por escrito o mediante cualquier otra forma de expresión, y de hacer uso para ello de cualquier medio de comunicación y difusión, sin que pueda establecerse censura. Quien haga uso de este derecho asume plena responsabilidad por todo lo expresado..."

Las constituciones de estos países también plantean claramente que los tratados nacionales aprobados por sus respectivos órganos legislativos o congresos nacionales son parte de la ley nacional. En el caso de Costa Rica, por ejemplo, el artículo 7 dice que: "Los tratados públicos, los convenios internacionales y los concordatos, debidamente aprobados por la Asamblea Legislativa, tendrán desde su

\footnotetext{
${ }^{i}$ Constitución de Nicaragua, 1987, tumado de http//:www.georgetown.edu/pdba/Constitutions/Nica/nica87.html, 9 mayo de 2005.

${ }^{8}$ Constitución Política del Perú de 1993, tomado de http://www.georgetown.edu/pdba/ Constitutions/Peru/per93.htmI, 9 de mayo de 2005.

" Constitución de 1999, República Bolivariana de Venezuela, tomado de http:// www.georgetown.edu/pdba/Constitutions/Venezuela/ven1999.html, el 9 de mayo de 2005 .
} 
promulgación o desde el día que ellos designen, autoridad superior a las leyes. (...)".

Los tratados internacionales relacionados con la libertad de expresión y aprobados por los países latinoamericanos, miembros de la Organización de Estados Americanos (OEA) son la Convención Americana de Derechos Humanos (o Pacto de San José) y el Pacto Internacional de Derechos Civiles y Políticos. Paralelamente, los países en estudio adoptaron la Declaración de Principios sobre la Libertad de Expresión, promovida por la Comisión Interamericana de Derechos Humanos.

Los artículos 2 y 8 de la Convención Americana de Derechos Humanos ${ }^{10}$ regulan lo que los estados miembro de la OEA deben cumplir en sus sistemas judiciales para garantizar los derechos de los individuos. El artículo $2 \mathrm{com}$ promete a los Estados Parte a "adoptar con arreglo a sus procedimientos constitucionales y a las disposiciones de esta Convención, las medidas legislativas o de otro carácter que fueren necesarias para hacer efectivos" los derechos y libertades tutelados por la Convención. Esto en caso de que no estuviere ya garantizado por disposiciones legislativas o de otro carácter. Mientras tanto, en el articulo 68 los Estados se comprometen "a cumplir con la decisión de la Corte (Interamericana de Derechos Humanos) en todo caso en que sean partes".

El artículo 13 de la Convención Americana de Derechos Humanos, el que más nos interesa en este caso, establece en lo fundamental que: "Toda persona tiene derecho a la libertad de pensamiento y de expresión. Este derecho comprende la libertad de buscar, recibir y difundir informaciones e ideas de toda índole, sin consideración de fronteras, ya

\footnotetext{
${ }^{10}$ La Convención Americana de Derechos Humanos fuéaprobada en la Conferencia Interamericana Especializada en Derechos Humanos, en San José, Costa Rica, el 22 de noviembre de 1969
} 
sea oralmente, por escrito o en forma impresa o artística, o por cualquier otro procedimiento de su elección". Adicionalmente, garantiza que "El ejercicio del derecho previsto en el inciso precedente no puede estar sujeto a previa censura sino a responsabilidades ulteriores, las que deben estar expresamente fijadas por la ley y ser necesarias para asegurar: a) el respeto a los derechos o a la reputación de los demás, o b) la protección de la seguridad nacional, el orden público o la salud o la moral públicas"11

El artículo 29 de la Convención Americana de Derechos Humanos esclarece las normas para la interpretación de la Convención y plantea que: "Ninguna disposición de la presente Convención puede ser interpretada en el sentido de: a) permitir a alguno de los Estados partes, grupo o persona, suprimir el goce y ejercicio de los derechos y libertades reconocidos en la Convención o limitarlos en mayor medida que la prevista en ella (...) d) excluir o limitar el efecto que puedan producir la Declaración Americana de Derechos y Deberes del Hombre y otros actos internacionales de la misma naturaleza".

Por su parte, el Pacto Internacional de Derechos $\mathrm{Ci}$ viles y Políticos en su artículo 19 establece, en su parte medular, que "1) Nadie puede ser molestado a causa de sus opiniones, 2) Toda persona tiene derecho a la libertad de expresión; este derecho comprende la libertad de buscar, recibir y difundir informaciones e ideas de toda índole, sin consideración de fronteras, ya sea oralmente, por escrito o en forma impresa o artística, o por cualquier otro procedimiento de su elección". ${ }^{12}$

\footnotetext{
${ }^{11}$ Convención Americana sobre Derechos Humanos (Pacto de San José), tomado de: http://www.oas.org^uridico/spamsli/tratados^ ${ }^{\wedge}$ - $32 . h t m l$, el 9 de mayo de 2005

${ }^{12}$ Pacto Internacional de Derechos Civiles y Políticos, tomado de http://www.unhchr.ch/ spanish/html/menu3/b/a_ccpr_sp.htm, el 9 de mayo de 2005.
} 
Finalmente, y en relación con las regulaciones de la libertad de expresión, los miembros de la OEA adoptaron, en 1993, el Protocolo de Managua o Declaración de Principios sobre libertad de expresión. En su artículo 6 esta declaración plantea que "Toda persona tiene derecho a comunicar sus opiniones por cualquier medio y forma. La colegiación obligatoria o la exigencia de títulos para el ejercicio de la actividad periodística, constituyen una restricción ilegítima a la libertad de expresión. La actividad periodística debe regirse por conductas éticas, las cuales en ningún caso pueden ser impuestas por los Estados"13

\section{Colegiatura versus libertad de expresión}

Para responder a la pregunta de si la colegiatura obligatoria de los periodistas es compatible o no con lo que establecen las constituciones, los tratados públicos, y los acuerdos internacionales y concordatos es necesario ofrecer algunos antecedentes. En las últimas dos décadas del siglo pasado algunos países latinoamericanos crearon los Colegios de Periodistas como un mecanismo de doble propósito: proteger los miembros que integraban estas corporaciones y garantizarle a la sociedad el derecho de recibir la información por parte de gente preparada ética y profesionalmente para esta labor. Lo que la ley establece, en términos generales, es que las funciones propias del periodista sólo pueden ser realizadas por miembros inscritos en el Colegio y que pueden ser miembros del Colegio aquellos profesionales graduados de una carrera universitaria en Periodismo (mínimo con grado de bachiller). En algunos casos se aceptaron como periodistas a personas que habían trabajado

\footnotetext{
"Declaración de Principios sobre Libertad de Expresión, Comisión Interamericana de Derechos Humanos, tomado de: hrtp://wwwddh oas.org/Basicos/Basicosl3-hhii, 9 de mayo de 2005.
} 
como tales durantes los cinco años previos a la creación del Colegio, aunque no tuvieran grado universitario ni estuvieran cursando la carrera.

El Colegio de Periodistas de Costa Rica argumentó en su momento ${ }^{14}$ que los colegios actúan en defensa del bien común y en defensa de sus miembros toda vez que "la colegiación obligatoria persigue fines de utilidad colectiva vinculados con la ética y la responsabilidad profesionales". También planteó que hay otro interés de mayor jerarquía que justifica la colegiatura obligatoria en algunas profesiones y es "asegurar una preparación adecuada y una estricta observancia de las normas éticas de la profesión, tanto por la índole de la actividad que realizan estos profesionales, como por la confianza que en ellos depositan las personas que requiere de sus servicios". Finalmente, el Colegio dijo que "la sociedad tiene derecho, en aras de la protección del bien común, de regular el ejercicio profesional del periodismo", y que "el manejo del pensamiento ajeno, en su presentación al público requiere no solamente del trabajo profesional capacitado, sino obligado en su responsabilidad y ética profesionales con la sociedad, lo cual tutela el Colegio de Periodistas de Costa Rica".

En 1985 el gobierno de Costa Rica le solicitó a la Corte Interamericana de Derechos Humanos (CIDH) una opinión consultiva relacionada con la interpretación de los artículos 13 y 29 de la Convención Americana de Derechos Humanos. En la consulta también se le solicitaba a la Corte determinar si existía o no incompatibilidad o contradicción entre la colegiatura obligatoria de los periodistas como requisito para ejercer la práctica del periodismo en

\footnotetext{
${ }^{14}$ Ver la Opinión Consultiva OC $-5 / 85$ del 13 de noviembre de 1985 del Gobiemo de Costa Rica a la Corte Interamericana de Derechos Humanos (La colegiatura obligatoria de periodistas, artículos 13 ; 29 de la Convención Americana de Derechos Humanos). Vale añadir que cumo consecuencia de esta Opinión Consultiva, varió por completo la forma como se r.malmente se concibieron los colegios de periodistas.
} 
general, y del reportero en particular, según el artículo 22 de la Ley 4420 o Ley Orgánica del Colegio de Periodistas de Costa Rica, y los artículos 13 y 29 de la Convención Americana de Derechos Humanos.

Para determinar si los colegios de periodistas restringen la liberta de pensamiento y de información la Corte Interamericana analizó a profundidad lo que el artículo 13 de la Convención Americana de Derechos Humanos dice. Este artículo claramente protege el derecho de las personas de "buscar, recibir y difundir informaciones e ideas de toda índole". Esto incluye no solo el derecho y la libertad de expresar los pensamientos sino también el derecho de "buscar, recibir y difundir pensamientos". En otras palabras, la restricción ilegal de este derecho es una violación no sólo a la libertad de expresión individual sino también al derecho de las demás personas de recibir información e ideas u opiniones. Es claro, en consecuencia, que la Convención Americana de Derechos Humanos está protegiendo el doble contenido de la libertad de expresión: el individual y el colectivo.

La Corte Interamericana de Derechos Humanos fue todavía más lejos al establecer que: "En su dimensión individual, la liberta de expresión no se agota en el reconocimiento teórico del derecho a hablar o escribir, sino que comprende, además, inseparablemente, el derecho de utilizar cualquier medio apropiado para difundir el pensamiento y hacerlo llegar al mayor número de destinatarios ${ }^{15}$. Para la Corte, la expresión y diseminación de ideas e información son conceptos individuales, de modo que cualquier tipo de restricción impuesta a la divulgación del pensamiento es una limitación directa al derecho de la persona de expresarse libremente.

${ }^{15}$ Opinión consultiva OC.5/S5 de la CIDH, 13 de noviembre de 1985 (punto no. 32), 
Adicionalmente, la C1DH estableció que la libertad de expresión tiene una dimensión social que debe ser considerada: la libertad de expresión es un medio para el intercambio de ideas e información y para la comunicación masiva entre los seres humanos, y ellos incluye, de nuevo, el derecho de cada persona de buscar y comunicar sus pensamientos a otras personas, así como recibir la opinión o pensamiento de otros. La Corte enfatizó que "para el ciudadano común tiene tanta importancia el conocimiento de la opinión ajena o de la información de que disponen otros como el derecho a difundir la propia". ${ }^{16}$

Otro de los aspectos que la C1DH dejó en claro es el alto valor que tiene la libertad de expresión, al reafirmar que las garantías de libertad contenidas en la Convención Americana de Derechos Humanos fueron diseñadas para ser las más generosas y para reducir al mínimo las restricciones a la libre circulación de ideas ${ }^{17}$. De hecho, insistió en la máxima de que "si a una misma situación son aplicables la Convención Americana y otro tratado internacional, debe prevalecer la norma más favorable a la persona humana"18.

En relación con la obligatoriedad de la colegiación de los periodistas, la Corte estableció que no toda transgresión al artículo 13 de la Convención Americana implica la supresión radical de la libertad de expresión. En efecto, la afiliación obligatoria de los periodistas a un colegio no necesariamente significa que se esté suprimiendo la libertad de expresión. Pero ese no era el problema en el caso que nos ocupa. La dificultad emerge cuando un acto del poder público "implique una restricción al derecho de buscar, recibir, y difundir informaciones e ideas, en mayor medida o

\footnotetext{
It ibidem

17 O.C. $-5 / 85, \mathrm{CIDH}, 13$ de noviembre de 1985 (punto 50).

15 O.C. $-5 / 85, \mathrm{CIDH}, \mathrm{i} 3$ de noviembre de 1985 (punto 52).
} 
por medios distintos de los autorizados por la misma Convención"19 , y este sí era el caso de los colegios de periodistas.

\section{El caso de Costa Rica}

En el caso específico de Costa Rica ${ }^{20}$, la ODH consideró que el requisito de la colegiación obligatoria de los periodistas sí constituía una restricción a la libertad de expresión para quienes no fueran miembros del colegio. El argumento que esgrimió la Corte fue la imposibilidad de otros (no periodistas) para ejercer el derecho a la libertad de expresión y la responsabilidad penal contra aquellos que ejercieran este derecho si autorización del Colegio.

Nuevamente la Corte dejó en claro que el derecho de comunicar información e ideas de cualquier tipo y por cualquier medio que la persona elija no estaba protegido por la legislación costarricense. Por el contrario, quienes buscan y transmiten información e ideas de todo tipo eran considerados "intrusos" o transgresores, por lo que se acusaba de ejercicio ilegal de la profesión de periodismo.

Previo a la opinión consultiva de la CIDH de 1985, la Comisión Interamericana de Derechos Humanos había mantenido, en el caso Stephen Schmidt contra el Colegio de Periodistas de Costa Rica, que "no hay oposición a la supervisión y control del ejercicio de las profesiones, ya sea que se haga directamente a través de oficinas de gobierno, o indirectamente por medio de una autorización o delegación hecha para ese propósito a través de un estatuto para la organización o asociación profesional (...) La membresía de los periodistas no implica ninguna restricción a la libertad de opinión y de expresión, sino una regulación que el

${ }^{19}$ O.C. $-5 / 85, \mathrm{CIDH}, 13$ noviembre de 1985 (puntos 54 y 55).

20 Ver Ley Orgánica del Colegio de Periodistas de Costa Rica o Ley No. 4422. 
poder Ejecutivo puede hacer para la validación de grados académicos, así como para la calidad de de su práctica" ${ }^{12}$. Posteriormente., la CIDH dijo, en la opinión consultiva solicitada por Costa Rica, que las organizaciones profesionales en general, a través de colegios profesionales, no son contrarias a la Convención (Americana de Derechos Humanos), y son un medio de regulación y control de la actuación de la fe pública y de la ética a través de la actuación de los colegas. Pero recordó que el concepto de orden público reclama que, "dentro de una sociedad democrática, se garantice las mayores posibilidades de circulación de noticias, ideas y opiniones, así como el más amplio acceso a la información por parte de la sociedad en su conjunto". ${ }^{22}$

El dilema, según la CIDH, es que el artículo 13 de la Convención Americana es muy claro en proteger la libertad de cada persona de "buscar, recibir y difundir información e ideas de todo tipo ... ya sea oralmente, por escrito o en forma impresa", que es también lo que hacen los periodistas. Dado que este no es el caso de otras profesiones, como las que ejercen los médicos o los abogados, las razones que se aplican regular el ejercicio profesional de la medicina, el derecho u otras, no son las mismas que se aplican al periodismo. Para la Corte no hay distinción entre la liberta de expresión y la práctica profesional del periodismo, dado que ambas se entrelazan. En consecuencia, la Corte estableció que:

Las razones de orden público que son válidas para justificar la colegiación obligatoria de otras profesiones no pueden invocarse en el caso del periodismo, pues conducen a limitar de modo permanente, en perjuicio de los no colegiados, el derecho de hacer uso pleno de las facultades que

\footnotetext{
${ }^{21}$ Caso No. 9178 de la Comisión Interamericana de Derechos Humanos (1984).

22 O.C. $5 / 85$, CIDH. 13 de noviembre de 1985 (punto no. 69).
} 
reconocen a todo ser humano el artículo 13 de la Convención (Americana de Derechos Humanos), lo cual infringe principios primarios del orden público democrático sobre el que ella misma se fundamenta ${ }^{23}$.

Además, la Corte dijo que un sistema de control del derecho a la libertad de expresión en nombre de una supuesta garantía de la corrección y veracidad de la informa. ción que la sociedad recibe puede ser fuente de grandes abusos y, en el fondo, viola el derecho a la información que tiene derecho esa misma sociedad. Es decir, es harto contradictorio invocar una restricción a la libertad de expresión como un medio para garantizarla ${ }^{24}$.

Todos estos argumentos condujeron a la CIDH a concluir que la Ley del Colegio de Periodistas de Costa Rica no permite a quienes no son sus miembros ejercer la práctica del periodismo, y limita el acceso al colegio solo a graduados universitarios que se han especializado en ciertos campos, lo cual no es compatible con el artículo 13 de la Convención Americana. También concluyó que el artículo 22 de la Ley del Colegio de Periodistas, el cual establece que "las funciones propias del periodista, sólo podrán ser realizadas por miembros inscritos en el Colegio", era incompatible con el artículo 13 de la Convención.

Posteriormente, la opinión consultiva de la Corte proveyó la teoría para sustentar el veredicto en el caso Róger Ajún contra el Colegio de Periodistas de Costa Rica ${ }^{25}$. Ajan, un comentarista de deportes, quien fue demandado por "ejercicio ilegal de la profesión de periodista", apeló a la Sala Constitucional solicitando la declaratoria de inconstitucionalidad del artículo 22 de la Ley Orgánica del

\footnotetext{
${ }^{23}$ O.C. $-5 / 85, \mathrm{CEDH}, 13$ de noviembre de 1985 (punto no, 76).

${ }^{24}$ O.C. $-5 / 85$. CIDH, 13 de noviembre de 1985 (punto no. 77).

${ }^{25}$ Exp. 0421-S-90. № 2313-95, Sala Constitucional, Corte Suprema de Justicia (1995)
} 
Colegio de Periodistas de Costa Rica. Argumentó que dicho artículo era incompatible con el número 7 de la Constitución Política de Costa Rica (el que le da preeminencia a los tratados internacionales sobre las leyes nacionales) y el artículo 13 de la Convención Americana.

El juez Solano Carrera dio el pronunciamiento de la Sala. Lo primero que indicó fue que el principio de la libertad de expresión de la Convención Americana no puede ser restringido por ningún medio directo o indirecto., ni por ningún medio que tienda a impedir la comunicación o circulación de ideas y opiniones. Solano enfatizó en el derecho de la persona de buscar, recibir y difundir toda clase de información por cualquier medio que la persona escoja o desee. En este sentido, la Sala acogió el argumento de Ajún de que el Colegio de Periodistas restringe las actividades relacionadas con la búsqueda, recepción y difusión de información a ciertas personas (periodistas con grado universitario). "Lo más serio", agregó el juez, "es que la Ley (del Colegio de Periodistas) define como funciones del periodista, justo aquellas que la Convención Americana establece como libertades individuales, por ejemplo, buscar, recibir y difundir información, lo cual es una coincidencia que no es encuentra en ningún otro derecho fundamental" 26 .

Para la Sala constitucional el hecho de que el gobierno de Cosía Rica hubiera solicitado a la CUDH una opinión consultiva no fue irrelevante. De hecho, al hacer esa consulta el gobierno de Costa Rica decidió confirmar de manera formal la opinión de aquella Corte. En este sentido, a criterio del juez Solano la opinión consultiva no deja ninguna duda cuando establece que:

1. La colegiación obligatoria de los periodistas es incompatible con el artículo 13 de la Convención Americana de

2h Itidem 
Derechos Humanos en cuando impide el acceso a cualquier persona al uso pleno de los medios de comunicación social como vehículo para expresar opiniones o para transmitir información.

2. La ley orgánica del Colegio de Periodistas de Costa Rica es incompatible con el artículo 13 de la Convención Americana de Derechos Humanos en cuanto impide a ciertas personas pertenecer al Colegio de Periodistas y, por consiguiente, el uso pleno de los medios de comunicación social como vehículo para expresarse y transmitir información.

La Sala Constitucional de Costa Rica también concordó con la $\mathrm{CEDH}$ en que la libertad de expresión requiere que la comunicación deba ser potencialmente abierta y sin discriminación, de modo que no haya individuos o grupos excluidos del acceso a los medios de comunicación. Más importante aún, la CBDH estableció que "tales medios de comunicación deben ser, en la práctica, verdaderos instrumentos para proteger esa libertad (de expresión) y no vehículos para restringirla $27 "$

Como resultado de estos argumentos, la Sala Constitucional no solo ratificó en toda su extensión la interpretación de la Convención Americana sino que declaró inconstitucional la colegiatura obligatoria de los periodistas y desde entonces nadie puede ser acusado en Costa Rica por ejercicio ilegal de esta profesión.

La opinión consultiva de la CIDH también fue piedra angular en las decisiones que tomaron las cortes constitucionales en República Dominicana y Colombia. En 1989 la Corte Suprema de República Dominicana desechó el artículo de la Ley 148 que había creado el Colegio de Periodistas

${ }^{27}$ O.C. $-5 / 85$, op.cit. (punto no.34). 
de ese país. Más tarde, en 1998, la Corte Constitucional de Colombia declaró inconstitucional una ley que regulaba el ejercicio del periodismo, la cual establecía requisitos para el ejercicio de la presión del periodismo.

Aun cuando algunos países latinoamericanos han tratado de regular la libertad de opinión, de pensamiento, de información y de expresión de diferentes formas, las decisiones tomadas por las cortes de Costa Rica, República Dominicana y Colombia no han sido secundadas por el resto de países donde la colegiatura de los periodistas es aún obligatoria. Por el contrario, en diciembre 2000, el Congreso Nacional aprobó la ley que creó el Colegio de Periodistas de Nicaragua ${ }^{28}$, y estableció (artículo 4) que los periodistas deben contar con la autorización del respectivo colegio para la práctica de su profesión. Se puede inferir, sin embargo, que eventualmente la colegiatura podría declararse ilegal en aquellos países donde todavía es obligatoria (Chile, Honduras, Perú y Venezuela).

\section{Conclusión}

Los países latinoamericanos protegen constitucionalmente el derecho de las personas de comunicar sus opiniones, ya sea de forma escrita o verbal. Por otra parte, todos los países han incorporado dentro de su legislación los tratados y acuerdos internacionales que protegen la libertad de opinión y expresión. Existe un reconocimiento generalizado de que el libre flujo de ideas no debe ser restringido por el requisito legal de ser miembro de un gremio, corporación o colegio, o por el de tener un grado universitario que lo acredite para laborar como periodista, aunque en algunos países ello todavía es un requisito. No hay duda de

\footnotetext{
${ }^{28}$ Ley no. 372 del Congreso de Nicaragua. Creacuin del Colegio de Periodistas de Nicaragua, 14 diciembre del 2000.
} 
que aquellos países en donde la colegiatura obligatoria es aún un requisito para la práctica del periodismo están restringiendo la libertad de expresión no solo de quienes deseen comunicar sus ideas, sino de quienes deseen recibir las ideas de otros.

La opinión consultiva de Costa Rica ante la CIDH, el veredicto de la Sala Constitucional en el caso Ajún contra el Colegio de Periodistas de Costa Rica, así como los veredictos de las cortes de República Dominicana y Colombia nos proveen de evidencia suficiente para afirmar que la colegiatura obligatoria de los periodistas es ilegal y contradice el derecho humano de la libertad de expresión, consagrado por la Convención Americana de Derechos Humanos.

Los veredictos de los casos mencionados han clarificado que le derecho de la información no es un privilegio de los periodistas. Tampoco es un derecho que los gobiernos deban otorgar a sus ciudadanos. Por el contrario, el acceso a la información es un derecho elemental de cada individuo, quien tiene el derecho dual no solo de ser informado sino de transmitir la información, utilizando cualquier medio que desee, incluidos los periodísticos. 